\title{
Newly discovered rock art sites in Balandar, Mashhad province, north-eastern Iran
}

\author{
Dario Sigari ${ }^{1, *}$, Mahmoud Toghrae ${ }^{2} \&$ Hassan Basafa $^{2}$
}

\section{Introduction}

The site of Pire Mazar Balandar (or PMB001) is located near the village of Balandar in the Khorasan region of north-eastern Iran $\left(33^{\circ} 09^{\prime} 37.64^{\prime \prime} \mathrm{N}, 59^{\circ} 29^{\prime} 52^{\prime \prime} \mathrm{E}\right.$; Figure 1$)$. It consists of an outcrop of volcanic rock on a mountain peak $(1532 \mathrm{~m}$ asl) on the north-eastern side of the Binaloud range, above the city of Mashhad (Figure 2).

The outcrop at PMB001 is $1.2 \mathrm{~m}$ wide and $0.75 \mathrm{~m}$ long, and faces south-east. It is decorated with 16 simple symbols positioned with almost no superimposition: three axes, a spiral, a double circle, two pairs of parallel U-shaped lines, a single U-shaped line, a group of curved lines and a line shaped like a question mark (Figure 3).

The site was well known to local inhabitants, but was only documented archaeologically following its discovery in 2015 by Mahmoud Toghrae. PMB001 is considered a sacred stone by local worshippers, who believe that the U-shaped engravings are hoof prints of the horse of the prophet Imam Reza, who is buried in the Mashhad shrine. Pilgrims, who leave votive offerings such as miniature objects, or candles whose melted wax covers part of the rock surface, had begun building a small temple until stopped by the archaeologists' intervention (Figure 4).

Fieldwork undertaken in August 2016 aimed to document and record the rock art at PMB001 through a contact tracing, adopting a procedure developed by the Coop. Arch. 'Le Orme dell'Uomo' (Arcà et al. 2008). A brief survey undertaken in the area around Balandar village, after the documentation of PMB001, led to the discovery of another rock art group, labelled BRA (Balandar rock art), located in a small creek, close to the road to Deh Gehibi. Here, petroglyphs are engraved on vertical schist panels, randomly distributed along the northern bank of a small seasonal creek. The subjects represented are zoomorphs and anthropomorphs, similar to those found all over the Iranian plateau (Naserifard 2007; Sigari 2016). Patination suggests that they may be of some antiquity. Work to catalogue these petroglyphs is ongoing and the results will be discussed in greater detail in a further publication. In the absence of any other archaeological evidence from the vicinity of PMB001 and BRA, the dating of the petroglyphs must rely on comparisons with the wider context of the Khorasan region and its archaeological landscape.

\footnotetext{
Università degli Studi di Ferrara, Corso Ercole I d'Este 32, Ferrara, Italy

University of Neyshabour, Adib Boulevard, Basij Town, Neyshabour, Khorasan Razavi province, Iran

Author for correspondence (Email: sgrdra@unife.it)
} 


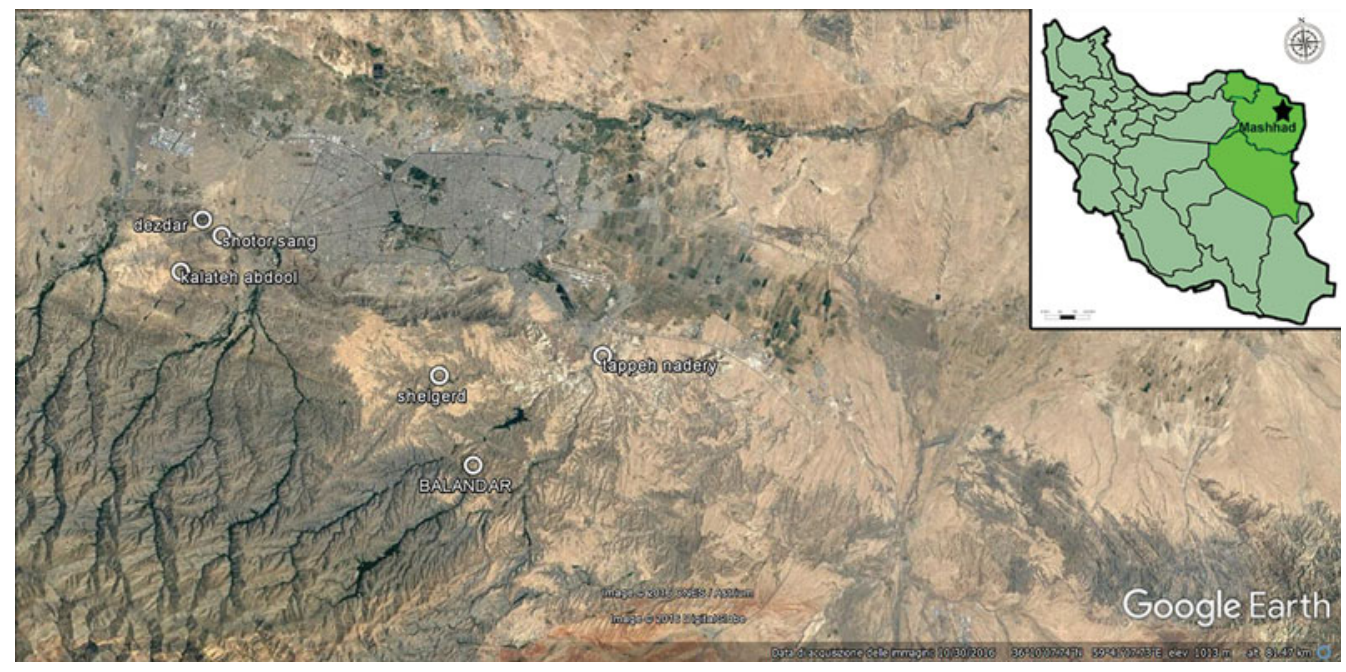

Figure 1. Map of Iran showing the location of Mashhad, Balandar and other rock art and archaeological sites (base map: Google Earth; edited by D. Sigari and M. Toghrae).

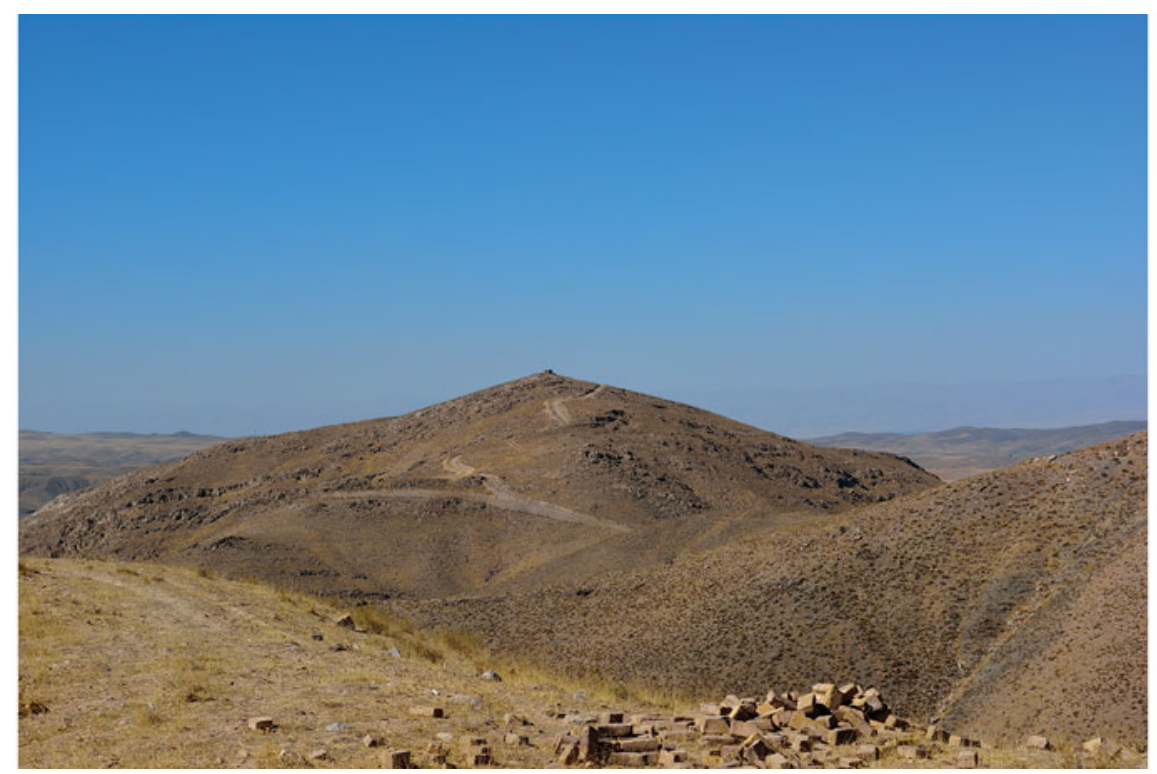

Figure 2. Panoramic view of the mountainous location of PMB001 (photograph: D. Sigari).

The location of PMB001 permits sweeping views across the Mashhad Plain, including Tappeh Nadery (Habibi et al. 2011), which is visible at a distance of $11 \mathrm{~km}$. This site is an artificial hill (Figure 5) preserving a long-term archaeological sequence, from the Chalcolithic to the Parthian period, testifying to continuous occupation of the region (C) Antiquity Publications Ltd, 2017 
Newly discovered rock art sites in Balandar, Mashhad province, north-eastern Iran

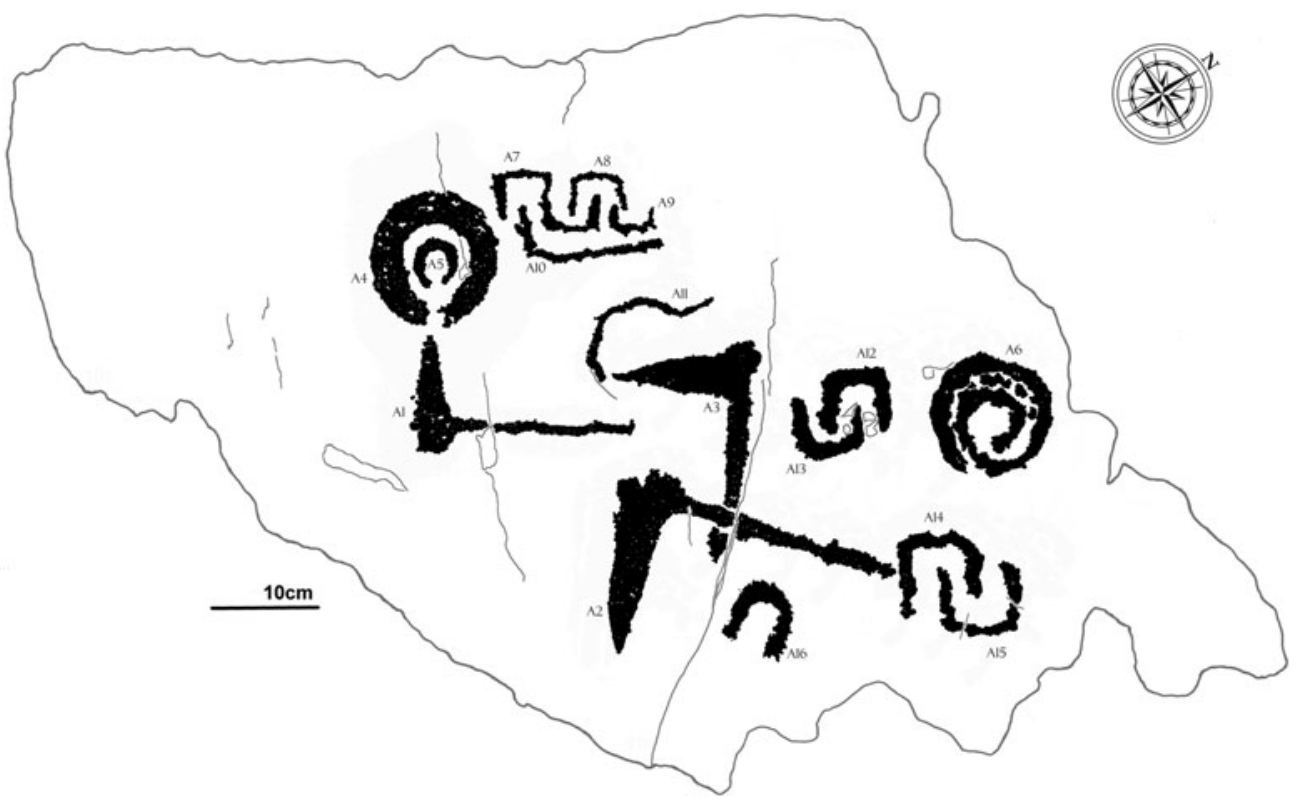

PMB001 26/08/2016 D. Sigari, M. Toghrae

Figure 3. Tracing of PMB001 (tracing: D. Sigari and M. Toghrae).

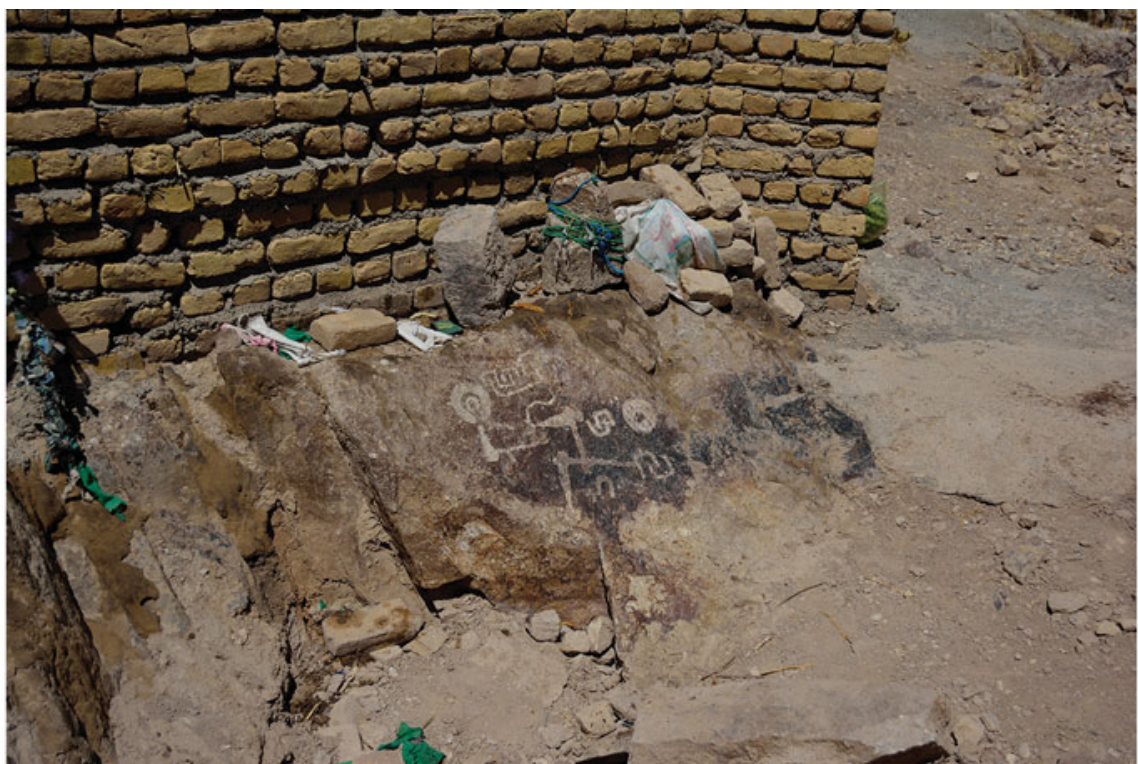

Figure 4. Photograph of PMB001. On its top are candles, stones and prayer beads offered by the worshippers to the prophet Imam Reza (photograph: D. Sigari). 


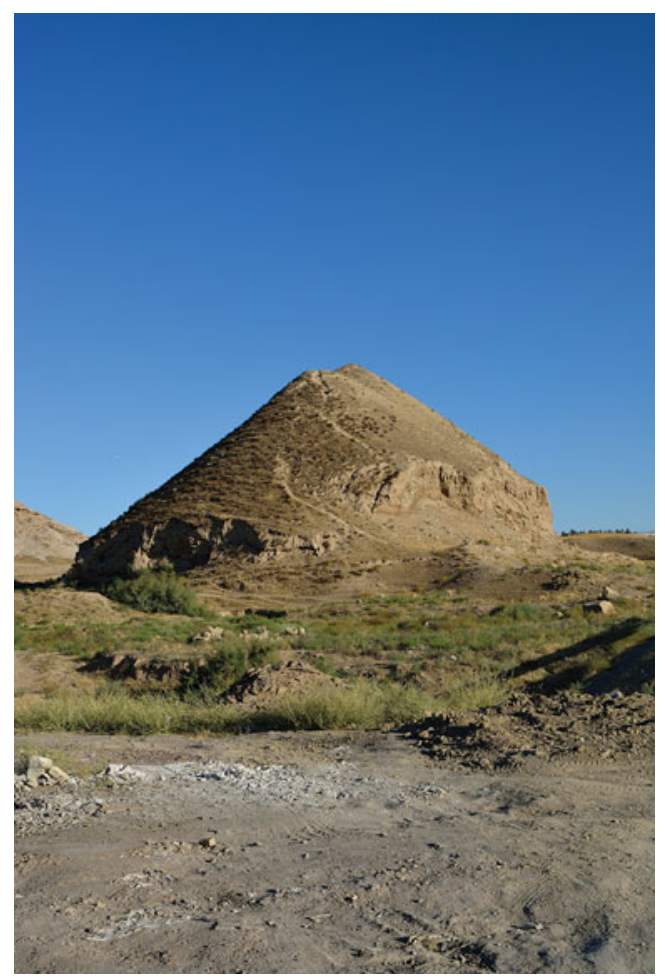

Figure 5. Photograph of the site of Tappeh Nadery (photograph: D. Sigari).

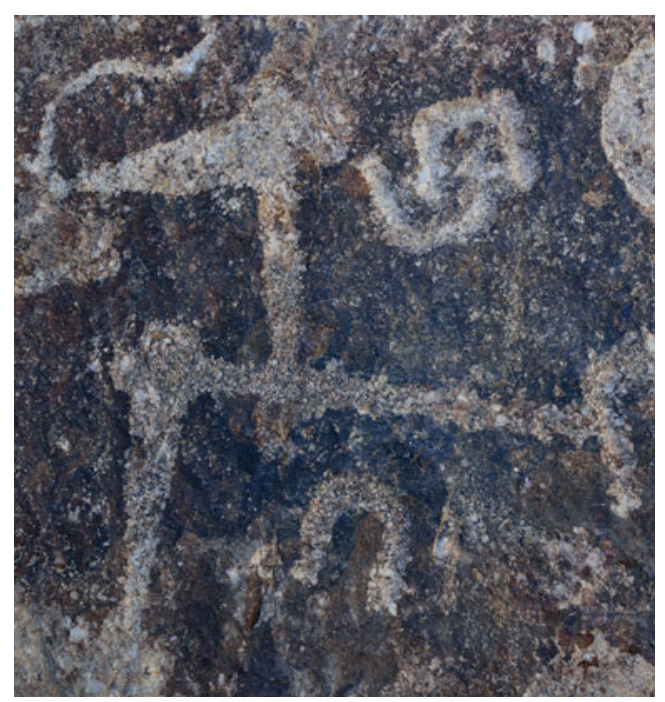

Figure 6. Axe figure A2 overlapping A4. It is the only superimposition of symbols on PMBOO1 (photograph: D. Sigari).
(Habibi et al. 2011). If subsequent dating of the axes represented at PMB001 (Figure 6) points to the Bronze Age, as with those recently published by Begemann et al. (2008: 62-63), this may indicate some type of link between the two sites and wider use of the landscape. The circular symbols, A4 and A5, are comparable to those found at Jorbat, which have been attributed to the Bronze Age or later (Vahdati 2012). Without any chronologically diagnostic symbols or any superimposition, however, the dating of the rock art currently remains unknown.

Both PMB001 and BRA present new questions in relation to the wider catalogue of rock art from the Khorasan region where other prehistoric rock art sites are known, including Shotor Sang, Kalateh Abdol, Bishiklik and the Toos Plain (Vahdati 2012; Saffaran \& Mozhdekanloo 2014; Rezaei et al. 2016; Sigari 2016). These sites demonstrate how the recurrence of some motifs indicates the long-term use of the same subjects and symbols, making it difficult to advance any chronological framework (Vahdati 2012). The case of PMB001, however, is a reminder that, regardless of the date at which they were first created, such sites can be used and adapted in later periods, and right through to the present.

Our research is ongoing. The next steps of the investigation will focus on the evidence for the location of rock art in different parts of the Mashhad landscape. At Balandar, for example, rock art has been found at the top of a mountain and along the course of a river, suggesting the possibility that distinct locations may correspond to different meanings. One of these, PMB001, perhaps with perceived greater sacred value, was later adapted in

(C) Antiquity Publications Ltd, 2017 
the light of new beliefs. Such repurposing of rock art for new beliefs and rituals will form another part of our ongoing research.

\section{Acknowledgements}

The authors would like to thank Mahmoud and Ali Sigari who helped to translate the Italian and English into Farsi.

\section{References}

Arcà, A., S. Casini, R.C. De Marinis \& A.E. Fossati. 2008. Arte rupestre, metodi di documentazione: storia, problematiche e nuove prospettive. Rivista di Scienze preistoriche LVIII: 351-84.

Begemann, F., E. Haerinck, B. Overlaet, S. Schmitt-Strecker \& F. Tallon. 2008. An archaeo-metallurgical study of the Early and Middle Bronze Age in Luristan, Iran. Iranica Antiqua 43: 1-66. https://doi.org/ 10.2143/IA.43.0.2024041

Habibi, K., B.S. Baikloo Islam \& A.A. Eshqi. 2011. Evidence from cultures of the Central Asia in Naderi Tepe, Mashad Plain, in northeastern Iran. MAGNT Research Report 3: 826-44.

NASERIfARD, M. 2007. Rock museums—rock arts (Iran petroglyphs). Arak: Navay-e Danesh.
Rezaei, M.H., S. Soleymani \& K. Ahmadi. 2016. Bishiklik petroglyphs in Neyshabur county, northeastern Iran. International Journal of Archaeology 4: 11. https://doi.org/10.11648/j.ija.20160402.11

Saffaran, E. \& Z. Mozhdekanloo. 2014. Proposed age of recently discovered petroglyphs of Iran's Toos Plain. Rock Art Research 31: 110-11.

Sigari, D. 2016. Piovono capre: i capridi nell'arte rupestre dell'Iran. TRACCE Online Rock Art Bulletin 39. Available at: http://www.rupestre.net/tracce/?p=11385 (accessed 24 March 2017).

Vahdati, A.A. 2012. A preliminary report on a newly discovered petroglyphic complex near Jorbat, the Plain of Jajarm, north-eastern Iran. Paléorient 37: 177-87. https://doi.org/10.3406/paleo.2011.5429 